\title{
A Critical Analysis of Causation Rules in Marine Insurance
}

\author{
Bima Manopo ${ }^{\mathrm{a}, 1, *}$, Robert Merkin QC ${ }^{\mathrm{a}, 2}$ \\ ${ }^{\text {a }}$ Faculty of Law, University of Exeter, United Kingdom \\ ${ }^{1}$ manopo.bima@gmail.com*; ${ }^{2}$ r.m.merkin@exeter.ac.ukmail \\ * corresponding author
}

\section{ARTICLE INFO}

Article history

Received: March 7, 2021

Revised: September 4, 2021

Accepted: September 30, 2021

Keywords

Marine;

Insurance;

Causation Rules;

\begin{abstract}
The United Kingdom has regulated Marine Insurance in great detail in some laws and regulations, but these regulations do not seem to have been fully implemented. This study will discuss the Causation Rules in Marine Insurance. More specifically, this article has looked at the impact of the development of the causation rules in marine insurance after implementing MIA 1906. This study argues that the efficiency test is now be regarded as a historical precedent of the causation rules. What is clear is that the operation of the efficiency test alters the rule which previously relied on a question of law by looking at the latest cause of the loss to recognize a question of fact by measuring the most predominant cause of the loss. However, it does not mean that the newest cause of the loss is automatically disregarded. An immediate cause may be proximate if it has an efficient and predominant effect to cause the loss.
\end{abstract}

\section{Introduction}

Causation in marine insurance sets a legal basis in determining the liability of insurers. The leading authority has placed the proximate cause as a question of facts. Paradoxically, each case may have totally different facts that make the application of the proximate cause to be inconsistent. Consequently, it causes confusion in determining the proximate cause of a loss due to each case's great complexity of facts. An interesting argument by Black J who said that "I know of no problem in the whole science of the law more abstruse than that of causation". While it is true that causation in marine insurance is not easy to be consistent, it still has some coherent precedents that the courts can use. Therefore, the courts should stick to coherent precedents to ascertain the proximate cause of a loss to make their decision become entirely predictable (Leong et al., 2020).

Initially, the proximate cause was the nearest in time to the loss. However, it has been changed by Leyland Shipping CO Ltd v Norwich Union Fire Insurance Society Ltd. The case concerned about which one should be considered as the proximate cause of the sinking ship between the initial peril due to the holes caused by the torpedo and the subsequent peril in the form of the gale. The court held that the initial peril was the most efficient cause of the loss. It sets an important precedent because the courts should scrutinize the proximate inefficiency instead of relying on the nearest time rule. It suggests that the initial cause may become much more efficient to affect a loss than the latest cause. However, the new rule raises a new issue (Kar \& Navin, 2021). 
Abandonment of the initial rule may create an issue to identify the proximate cause. It is because the new rule provides a space to recognize multiple causes. Generally, where there are more than one or more various causes, one of them should be selected as the most efficient cause to create a loss. However, it is not easy to apply when there are two equal efficient causes. For example, suppose one of them is insured by a policy. In that case, it will not automatically make the insurer to be liable because two conditions should be assessed whether there is an excluded peril or an uninsured peril operating concurrently with the insured peril. These conditions have different results. If they operate concurrently, the excluded peril prevails over the insured peril, and the insurer is not liable in this situation. In contrast, the insurer is liable if the uninsured peril and the insured peril work in conjunction to cause a loss due to the operation of the insured peril. These rules are the main legal precedent in a situation where there are two causes operating concurrently (Zheng et al., 2020). However, although the rules have become a question of law, they are not a strict rule in practice. It can be seen after the decision of the Global Process Systems Inc v Syarikat Takaful Malaysia Berhad (The Cendor Mopu), where the courts held that inherent vice and perils of the sea could not occurred concurrently to cause a loss.

This case is important because it imposes liability on insurers in a situation where there is a peril of the sea that has intervened in the process of inherent cause to cause a loss. In addition, it makes causation in marine insurance to be more complicated. It may deny the rule stating that the excluded peril takes priority over the insured peril. For instance, if in a situation where there are two competing causes involving the excluded peril is inherent vice and the insured perils are perils of the sea, the excluded peril cannot take over due to there being any concurrent proximate causes in such situation. It demonstrates that consistency is not guaranteed in the application of the proximate cause (NG, 2010).

A potential issue arises as to which one should be followed between a question of fact or a question of law in applying the proximate cause. However, essentially, consistent results of the application of the proximate cause should be made to give benefits, such as predictability, for both insurers and assureds. Hence, this study aims to find out the possibility of the consistent application of causation rules. Its aim is important to know how the established precedents should be followed. In order to achieve the aim, the research method will be based on an examination of relevant cases and statutory laws, especially the Marine Insurance Act 1906 (The MIA 1906), along with additional information provided by relevant law reports, journal articles, and books, that will give a comprehensive view on a possibility to apply proximate cause consistently. First, it will discuss the evolution of the proximate cause in marine insurance. Second, it will examine the application of the concurrent causes based on the leading cases to provide general causation rules. Third, it will expose some perils that generally lead to disputes between assureds and insurers and examine the application of the proximate cause in each peril. Fourth, it will examine the comparison between the old precedent and the new precedent to establish consistent rules of causation. This chapter will also derive some important principal rules from the relevant cases to reduce the issue of inconsistency. The study will conclude that inconsistency can be reduced by applying coherent principle rules to make predictable results (Nwafor \& Walker, 2020).

Section 55 (1) of the MIA 1906 is silent about the definition of the proximate cause. Thus, it is important to describe the definition of the proximate cause. Prior to the MIA 1906, the rule to ascertain a proximate cause was by applying the chain of the cause in a time frame. It means that the last or immediate cause to the loss was deemed as a proximate cause in the point of time, in Pink v Fleming, where the ship was involved in a collision during its voyage. The ship was repaired, and a part of the goods was discharged to support its repairs. After completion of the repairs, the discharged goods were handled and reloaded to the ship's board. Consequently, the process of the repairs and the reloading led to delay, and a few goods were damaged on arrival. An issue arises as to whether the collision or the delay and the handling of the goods should be considered the proximate cause. The court held that the proximate cause was the delay and the handling of the goods, not the collision. The court reaffirmed the way marine insurance recognized the proximate cause at that time by stating, "the last cause only must be looked to, and the others rejected, although the result would not have been produced without them". It made the proximate cause to be a question of law. It had been sustained as the rule of law until the application of the proximate cause inefficiency (Dupré \& Perluss, 2016). 
In Leyland Shipping Co Ltd v Norwich Union Fire Insurance Society Ltd, in which the House of Lords replaced the prevailing view that the proximate cause was the latest cause of the loss. The Ikaria was insured under a policy covering perils of the sea but excluding war perils. During its voyage, it was hit by a torpedo launched by a submarine. Although it had severe damage of two holes which the torpedo made, it successfully reached the outer harbor of Le Havre. However, it eventually sank due to the gale, because of leakage from the holes caused by the torpedo. The issue was the proximate cause of the total loss of the ship. If the proximate cause were the torpedo, the insurer would not be liable for the exclusion policy. In contrast, the insurer would be liable if the loss was caused by the gale (Hee et al., 1999). The House of Lords held that the loss caused by the torpedo by applying a new precedent to ascertain the proximate cause, in which the proximate cause in efficiency. It is noteworthy that causation is a net instead of a chain. It makes the new precedent is more accurate and reasonable than the previous precedent. It is because where a ship sails, it has many possibilities to be exposed by risks even in a short period of a voyage, and every event may lead to various incidents in which one of them may subsequently become an immediate cause to a loss. However, the immediate cause may have a causal link to the previous event and is unlikely as an efficient cause of the lost. In other words, the inception of the risk is more likely to be the proximate cause of a loss rather than the latest one. Considering the first peril by looking at its possibility to generate a loss is a major distinction between Pink v Fleming and Leyland Shipping Co Ltd v Norwich Union Fire Insurance Society Ltd. However, under particular circumstances, an intervening cause will break the net of causation (Abbott \& Holland, 2013).

An intervening cause is an independent event that comes between the initial event and the final loss. If an intervening cause occurs after the occurrence of an insured peril, the proximate cause will be superseded from the insured peril to the intervening cause. It is illustrated in Lind v Mitchel, where the ship was damaged by ice and severely leaked. Then, the master set fire to the ship to prevent potential danger to navigation, and it was abandoned afterwards. Eventually, the ship sank long after it was burned and abandoned. The court held that the loss was proximately caused by the unreasonable abandonment of the ship, which means that negligence of the master prevailed over the leakage. However, not all intervening causes will break the net of causation because only the intervening cause that is predominantly efficient to be considered as the proximate cause. Thus, in the absence of any other intervening cause, an insurer will be liable to the loss caused by the initial peril as long as it is satisfied to be agreed following the parties' intentions or common sense view (Akyuz, 2015).

It is noteworthy that the test of efficiency should use a commonsense view. The view does not require the judges to use sophisticated knowledge to ascertain the proximate cause of a loss. It is because "causation is to be understood as the man in the street and not as either the scientist or the metaphysician, would understand it. Cause here means what a business or seafaring man would take to be the cause without too microscopic analysis but on a broad view." In addition, the courts should consider and examine the parties' intentions by looking at whether the facts correspond with the intentions of either parties to cover risks pursuant to the contract between them. It is because assureds and insurers usually find it difficult to find the precise words to describe the risks they want to cover (Van den Bergh et al., 2002).

The proximate inefficiency gives room for more than one proximate cause to generate a loss. It is because the level of reality, predominance, and efficiency of a particular cause does not prevent other causes to have an equal or nearly equal level with that cause to create the loss. It suggests that concurrent causes require more than one efficient cause to create the loss. These efficient causes fall into two categories, namely independent and interdependent causes. Concurrent proximate causes may arise not only in a situation that has independent causes but also in a situation where there are interdependent causes involved to cause a loss. Both of them are valid to be concurrent causes if their resulting loss is indivisible. The difference between these causes is that independent concurrent causes do not have a causal link between them because the link only exists between each of them and the loss, while interdependent concurrent causes are unable to cause the loss without a causal link among the causes. However, there is inconsistency whether concurrent proximate causes exists or not in a situation where there are two independent causes involving inherent vice and perils of the sea (Feichtner, 2020). 
In JJ Lloyd Instruments Ltd v Northern Star Insurance Co Ltd (The Miss Jay Jay), a case of a marine hull policy, where the ship was defectively designed for a trip from Hamble to Deauville. The faulty design made it be unseaworthy. During its return voyage to Hamble, the ship encountered adverse sea, and when the ship arrived at the port, it was found that it had suffered damage during its voyage to Hamble. One of the issues arose whether the faulty design and the adverse sea had an equal efficiency to cause the loss or not. The court held that both of them had the equal efficiency to cause the loss by using a commonsense view because the loss would not have occurred but for a combination of these independent causes. However, this case has an opposite position with the ruling of the Cendor Mopu in terms of the concurrent causes. The oil rig was transported from Texas to Malaysia on a barge with its three giant legs extending some 300 feet into the air. The oil rig was insured under an all-risk policy of the Institute Cargo Clause, in particular, an exclusion policy of clause stating that "loss, damage or expense caused by inherent vice or nature of the subject matter insured." During its voyage, the legs suffered a progressive cracking arising from fluctuated stresses. After reaching Saldanha Bay, the legs were repaired due to their fatigue cracking. However, an effort to repair the legs did not prevent them from breaking off. An important issue was that the court had to decide the proximate cause among possible causes (Chen et al., 2019).

The causes were an inherent vice, perils of the sea in the form of the stresses put upon the legs caused by the height and direction of the waves encountered by the barge, or a combination of them. To dismiss the concurrence of causes, the court held that the proximate was the perils of the sea because the loss caused by inherent vice only occurred in a situation where there is no intervention of any fortuitous accident or casualty. As a result, inherent vice could not work in conjunction with the perils of the sea to create the loss. It shows that if the loss is developed by any fortuitous external accident, the inherent vice is no longer an efficient chain to the loss. In contrast, in the absence of external causes, inherent vice remains to be efficient as long as the nature of the subject matter insured becomes the sole cause of the loss. Consequently, the test to ascertain the proximate cause will depend on the facts of each case along with the way of the courts to use common sense view, and insurers should stop using their defense based on inherent vice if there is an intervention of external causes to the loss. However, The Miss Jay is still relevant to follow for any courts as to indemnity in a situation where there are an uninsured peril and an insured peril operating concurrently (Tiller \& Richards, 2018).

According to The Miss Jay Jay, if there are two causes causing the loss concurrently, one is insured peril, and the other is uninsured peril, the assured will be entitled to cover. The rule is reaffirmed by IF P and C Insurance Ltd v Silversea Cruises Ltd, where the assureds claimed that their loss caused from the effects of the terrorist acts and the cancellation of reservations by passengers due to the warnings of the United States government as to the terrorist acts. The court held that the terrorist acts and the government warnings, which was covered by the policy, were concurrent cause to the business losses; however, the acts of terrorism were not expressly excepted in the policy and merely an essential precondition to the warnings and therefore, the insurers were liable to cover the loss. However, in a different situation, indemnity is not granted if there are two causes operate concurrently to the loss, one cause is excepted by the policy, and the other one is covered (Krauss, 2021).

In a non-marine case, Wayne Tank and Pump Co Ltd v Employers Liability Assurance Corp, where the factory was burnt after installing equipment for storing and conveying liquid wax. Two acts of negligence influenced the loss. The acts were the use of unsafe materials and the act of the engineers in turning on the equipment and leaving it unattended. Under the policy, the insurers were liable for "damage consequent upon damage to property as a result of accidents", meanwhile the policy had an exception of indemnity for "damage caused by the nature or condition of goods sold or supplied by or on behalf of the assured." The court held that the proximate cause was the nature of the goods that fell within the exception clause of the policy. However, Lord Dening established a strong obiter dicta, which is reaffirmed by some authorities, for a situation where assureds suffer a loss which is proximately caused by an insured peril and by an excepted peril, then exception precludes their recovery. Lord Dening's view sets an important precedent to balance the interests between assureds and insurers because his obiter dicta will limit assureds' expectation to gain recovery due to the operation of the exception clause. In contrary to The Miss Jay Jay, the position of assureds is superior to insurers because as long as there is an insured peril operating concurrently 
with an uninsured peril, the insured peril prevails. Therefore, once the concurrent causes exist, the policy plays a critical role to determine whether insurers must indemnify the loss or not by using either the principle of The Wayne Tank or the principle of The Miss Jay Jay. Both of them operates as the equilibrium of the interests between assureds and insurers (Abaei et al., 2018).

\section{Results and Discussion}

\subsection{The Evolution of the Proximate Causation Rules in Marine Insurance}

An "all risks" policy is introduced as a wide coverage for assureds. The Institute Cargo Clauses 2009 (the ICC 2009) has three coverage classes, namely A, B, and C. The policy is intended to cover "all risks whatsoever" as long as accidental causes and fortuitous accidents cause the loss. However, it does not cover a loss that must occur. Although the policy seems more favorable for assureds, it has some limitations, either based on the exclusions under the MIA 1906 or the test of inevitability. The proximity rules will be helpful for insurers to reject indemnity if they can prove that an exclusion peril proximately causes a loss.

The policy does not cover inevitable losses. It is because the inevitable losses are out of the concept of risks, which never covers certainty, for instance, in F.W. Berk and Co. Ltd. v Style, where the kieselguhr was insured under "all risk" policy. It was packed in paper bags. The bags were inadequate to endure during a voyage to London. It was held that the recovery was not granted by stating that the poor conditions of the bags could not hold their contents, which led to the loss, to be certain. This case shows that the inevitability of the loss is able to limit the application of the policy. Moreover, excluded losses under Section 55 (2) of the MIA 1906 and the insertion of some exclusionary clauses into the ICC 2009 can balance the interests between assureds and insurers. The construction of the policy should follow the notion of the freedom of contract. It means that although the policy relatively covers wide risks, the courts should consider clear and unambiguous exclusionary clauses which are mutually agreed by both parties to limit such risks. Consequently, the list of perils in the policy will be essential for both parties. In terms of the burden of proof, the test of proximity is important to examine whether insurers would be liable or not (Sabela-Rikhotso et al., 2021).

The policy requires an assured to prove a loss has been proximately caused by a fortuitous external accident or casualty to claim indemnity. In contrast, an insurer can protect themselves by providing all required evidence to show that the loss is not fortuitous. The insurer has a narrow scope to establish the proof by providing specific exclusions. For example, the insurer should prove that the loss has been caused by the inherent vice or nature of the subject matter insured. However, the initial burden of establishing the fortuitous external element of the loss is borne by the assured. If the assured can do so, it will preclude the relevance of the exclusions. Consequently, although the fortuitous element of the loss is subject to prima facie evidence, the burden of proof by the assured is relatively easier than the insurer because it is not necessary for the assured to prove a specific insured peril under an "all risks" policy (Fu et al., 2020).

Therefore, the battle of both parties will depend on which proof is more acceptable and reasonable before the courts, which will apply the rules of proximity. The critical consideration refers to the risks themselves which should be associated with fortuitous and accidental events. However, it is noteworthy that if there are two concurrent causes that have been clearly mentioned in the policy as exception perils, the exception prevails. In other words, the loss caused by an exception peril is irrecoverable.

The perils of the sea embrace a diverse range of risks in marine insurance. Assureds can claim indemnity if they successfully prove that their loss caused by perils of the sea unless the policy provides otherwise. However, it is impractical to define one by one peril which should be covered rather than suggesting the elements of perils of the sea. Therefore, it is necessary to notice two examples of perils of the sea before looking into their elements and the application of the proximity test, in Thomas Wilson, Sons, and Co v Owners of Cargo per The Xantho, where the ship sank after a collision with another ship during a voyage. The shipowners claimed that the loss of the ship was due to a peril of the sea in the form of a collision, which was an excepted peril. It was held that collision was a peril of the sea by stipulating that the peril must be casualty which should not be 
foreseen as one of the necessary incidents of the adventure (Lonergan, 2011). Another example of the perils of the seas is the ingress of water, which is subject to the reason of its entry. In Versloot Dredging BV v HDI Gerling Industrie Versicherung AG (The DC Merwestone), where the ship's crew did not drain the pump of seawater and failed to close the sea valve after chipping the ice off from the hatch cover by using the pump. Some seawater that remained in the hose and its filter froze and melted afterwards. Consequently, water entered the engine room and damaged the engine. It was held that an ingress of seawater caused by crew negligence was a fortuitous accident which typically constitutes a peril of the sea. However, if water entered the ship due to unseaworthiness in the form of debility of the ship, it would not be a peril of the sea. Hence, it can be concluded that the perils of the sea have different forms. Consequently, it is hard to select which perils should be defined as perils of the sea because every case has different circumstances. However, although collision and the ingress of water are different types of perils, they can be described as fortuitous events (Appleby et al., 2021).

The perils of the sea should be fortuitous or casualties of the sea, excluding the ordinary action of the winds and waves. The fortuitous element is one of the essential requirements. It is reaffirmed by Tucker J, who stipulated that no peril can be a peril of the sea unless the peril has the fundamental element of fortuitous. However, the element of fortuitous should be seen as a broad common sense, which means that this element cannot exclusively apply to unexceptional accidents, for example, unforeseeable weather. In fact, ordinary weather can still have an element of fortuitous. It is illustrated in The Cendor Mopu, where the three rig legs broke off on a barge in the weather, which was not beyond reasonably contemplated for its voyage. Lord Clarke stipulated that the critical consideration was the consequence of the action of the sea, which must be fortuitous. Similarly, Lord Mance stated that the ordinary action of the winds and waves must be investigated the action of them rather than their condition. This case is important to understand the meaning of perils of the sea under the statutory law because as long as an action of the sea has a fortuitous element to cause a loss, it can be categorised as perils of the sea, regardless of the state of the sea is being violent or not. In addition, it is noteworthy that perils of the sea are not similar to perils at sea in marine insurance. It is because a loss of the subject-matter insured at sea is not always related to the perils of the sea. For example, a ship that sinks as a result of its debility is excluded in the meaning of perils of the sea, although the ship is sunk by the incursion of water. Hence, a clear distinction between these perils should be based on the element of fortuitous. Perils of the sea must have an element of fortuitous, while not every peril at sea is fortuitous.

In terms of the principle of proximity, in a situation where inherent vice, which is one of the internal causes, is on a process to cause a loss, however during the process, a peril of the sea intervenes and efficiently causes the final loss. The proximate cause will be the peril of the sea. It is because the peril efficiently establishes a new link to the final loss, and both the peril of the sea and the inherent vice cannot operate concurrently. It has been well examined in The Cendor Mopu. Therefore, perils of the sea are an independent cause and able to make a new efficient causation link to a loss if they occur along with inherent vice (Sheng et al., 2021).

If a loss is caused by wilful misconduct, an assured will not be entitled to indemnity. Wilful misconduct occurs in a situation where a person deliberately or recklessly commits wrongful actions. In National Oilwell (UK) Limited v Davy Offshore Limited, Colman J stated that the act of wilful misconduct requires intentional action by an assured to cause a loss to claim its recovery and such intention must be wrongful pursuant to the contractual relationship under the policy. Furthermore, Diplock L.J stipulated that if an assured recklessly takes a course of action which he knows that such action ought not to be taken because the policy indemnifies his recovery against the loss, the nature of assured's action can be recognized as willful misconduct. It suggests that the essential elements of willful misconduct are intentional actions or recklessness by the assured to cause the loss to recover. These elements are satisfied to refrain indemnity for the assured under the policy on the basis that an insurance contract only covers perils that are fortuitous and is not intended to indemnify inevitable losses. The significant application of the wilful misconduct in marine insurance is to protect insurers from any wrongful action conducted by assureds who are intended to take benefits from their wrongful acts. It corresponds with a recognized legal principle that a person cannot take advantages of his own wrong. Hence, in terms of wilful misconduct, no room for assureds to cover their loss. 
Regarding the application of the proximate cause, it is not fully true that proximate cause cannot apply in a case involving the wilful misconduct because if a loss is caused by a peril insured against, as a result of a deliberate act of the assured, the proximate cause shifts from the peril to the action. In other words, the effect of the wilful misconduct effectively changes it to be the proximate cause. In Robert Thompson, Joseph Lowes Thompson and John Thompson v Thomas Duck Hopper, where Lord Campbell stipulated that the misconduct was unnecessary to be the causa causans on the basis that a person shall not take any benefit from his wrongful act. It corresponds to Trinder Anderson and Co v Thames and Mersey Marine Insurance Co, where Lord Justice Smith stated that although remote causes were irrelevant, the loss proximately caused by a peril insured against would be irrecoverable if it was also caused by a remote cause in the form of the wilful misconduct.

These two statements indicate that although the wilful misconduct is a remote cause, the loss caused by it is not recoverable. Consequently, the test of proximate cause seems to be immaterial. However, the effect of the wilful misconduct is sufficient to make it be the proximate cause. It is because the consequence of the wilful misconduct efficiently leads to the occurrence of the loss. Susan Hodges argues that if wilful misconduct operating as a remote cause is enough to prevent an assured from being indemnified, the stronger argument should exist by arguing that the indemnity is denied due to the misconduct is a proximate cause of the loss. It suggests that the effect of the wilful misconduct is acceptable to turn it from a remote cause to be a proximate cause of the loss. It is illustrated in Samuel v Dumas, where a ship was scuttled by the master and crew with the connivance of the owner.

The main issue arose whether the cause of the ship was due to a peril of the sea or the deliberate action. It was held that the proximate cause of the loss was the scuttling because the ingress of the water was the inevitable consequence of the act. It shows that the holding of the case is consistent with the efficient proximate cause rule and the exclusion rule. Therefore, if the wilful misconduct either partly or fully takes part to cause a loss, it undoubtedly becomes a proximate cause of the loss.

Ordinary wear and tear are an exception of indemnity unless the policy rules otherwise. Some Institute Cargo Clauses codify the exception in favor of insurers. The exception provides protection for insurers to ignore a loss from being recoverable. It is argued that ordinary wear and tear is contrary to the principle of insurance, which is against risks. No one ship is able to avoid suffering a particular degree of decay and diminution in value for any length of time during its operation, even in the most favorable circumstances. Ordinary wear and tear occur without the element of fortuitous or accidental, which are fundamental requirements of perils of the sea. Consequently, assureds would be liable for a loss caused by ordinary wear and tear (Feichtner, 2020).

Ordinary wear and tear can be found in Wadsworth Lighterage and Coaling Company Ltd v Sea Insurance Company Ltd, where a barge was insured against perils of the sea. The barge was moored in Coburg Dock after carrying out over 100 tons of coal. Unfortunately, it sank at her moorings on a calm night. In fact, it had spent 50 years of her service to carry out coal. It was held that the loss was proximately caused by ordinary wear and tear. Lord Justice Scrutton stated that the old age of the barge efficiently caused water came through the seams, and its own inherent weakness played a sufficient role to cause her sinking. However, if the loss is efficiently caused by a latent defect, ordinary wear and tear does not apply. The distinction between them is significant to determine who will be responsible for a loss because the latent defect is characterised as a peril under the Inchmaree Clause. In Prudent Tankers Ltd SA v The Dominion Insurance Co. Ltd (The Caribbean Sea), a tanker was insured under The Inchmaree Clause. The tanker was on duty to carry crude oil from Venezuela to Tacoma via the Panama Canal. After leaving the Panama Canal, the tanker sank after water entered the engine room due to the failure of the nozzle, although some engineers had checked out the tanker and pumped out the water. The court had to determine the cause of the loss, whether it was attributable to ordinary wear and tear or latent defect. It was held that the exclusion under section 55 (2) of the MIA 1906 did not apply because the loss was caused by the defective design of the nozzle, which had a latent defect, worked in conjunction with the welded joint to develop fatigue cracks which cause the ingress of water. These cases are essential to consider to what extent ordinary wear and tear should apply (Krauss, 2021).

The occurrence between ordinary wear and tear and the latent defect is impossible to exist concurrently. It means that one must occur, and the other must be disregarded. On a linear approach 
to causation, if there is a dispute involving wear and tear as exclusion and whether a loss is proximately caused by an insured peril, the fortuitous and accidental element of perils insured against will be a starting point before considering the final element of inevitability. It is because the test of proximity is in line with the principle of insurance policy that does not cover an inevitable loss. Therefore, if the loss is proximately caused by ordinary wear and tear, it is irrecoverable.

\subsection{Consistency of the Causation Rules in Marine Insurance}

The fundamental principle derived from the last time cause is that the courts established the groundwork for assessing the distinction between proximate causes and remote causes by using the nearest cause of the loss. Only the latest cause of the loss could be considered as a proximate cause and any other events that occurred before the last one should be held as remote causes. It could make consistent with ascertaining the proximate cause. Essentially, the latest cause of the loss became the operative cause, to be weighed against the other causes. It would generate a degree of consistency. According to Lord Brandon, certainty, consistency, and continuity can be reached in the field of commercial law if once court's decision has been made, it must be followed in the future on the basis of a similar account (Stebbings et al., 2020).

Similarly, Neil Duxbury argued that consistency to follow a particular precedent creates a possibility to argue that the court should be estopped from doing anything except following that precedent in the case at hand, and then by doing so, the holding of the court will be relatively predictable. Thus, if the starting point is that the loss must have been caused by a peril, then the courts only look at whether such peril had been covered in the policy and occurred immediately before the loss. For instance, in John Corry and Sons v Albert Edward Burr, where the ship was seized by Spanish revenue officers as a result of the barratrous act of the master in smuggling. The assureds proceeded to recover their expenses to release the ship. Although the policy of the ship included barratry of the master as one of the perils insured against, the insurers were not liable because the court held that the seizure was the direct and immediate cause of the loss pursuant to its warranty stating that "free from capture and seizure and the consequences of any attempts threat". Therefore, it might be the best rule to preserve consistency in finding the proximate cause. However, although it was a good law to maintain consistency, the result of it potentially lacks accuracy (Tiller \& Richards, 2018).

It is argued that the chain of time test has a potential flaw to determine an efficient and predominant cause that leads to the loss. The latest cause of the loss may be a subsequent event because of an influence by a prior cause unless there is an intervening cause. In Leyland Shipping Co Ltd v Norwich Union Fire Insurance Society Ltd, where the court held that the loss was caused by the torpedo instead of the gale because the real proximate cause was not merely the nearest cause but the main examination to ascertain the cause was by applying to what extent a cause has influenced the loss efficiently and predominantly. However, if the latest cause test had applied to this case, then the holding of the case would have been unreasonable because the holes caused by torpedo was not considered. It shows that the accuracy of proximate cause is not well established in the latest cause test because all substantial events occurred before the latest cause of the loss would be abandoned. For example, where a ship is involved in the collision, then it is necessary to repair the ship that may lead to delay, it is unusual to argue that any freight lost by reason of loss of use of the ship while under repair is proximately caused by delay instead of the collision. Hence, it is well established that the efficiency rule is more accurate and reasonable to ascertain the proximate cause of the loss, rather than the old rule. Then, a crucial question is whether the proximate cause inefficiency is unable to provide consistent rules. English Courts recognize the application of the commonsense view (Akyuz, 2015).

Unfortunately, it may become a subjective approach of judges because there is a possibility between two or more judges to have unequal perspectives in the case at hand. For example, In IF P and C Insurance Ltd v Silversea Cruises Ltd, where whether the terrorist act of the "9/11" could be considered as an act of war or not pursuant to the policy. Rix L.J argued that the " $9 / 11$ " was an act of war because acts of war could arise even in the absence of war, while Ward $\mathrm{J}$ contended by arguing that the real war itself should be interpreted narrowly as a war between identifiable parties, and the " $9 / 11$ " was merely an act of terrorism because the war of terror is only a rhetorical response to fight unidentifiable objects. It shows that commonsense view may produce unpredictable results. 
It is acknowledged by Knutsen who argues that the proximate cause of loss based on the common view, as applied in the English Courts, may create unpredictability because the predominant cause is scrutinized by looking at the facts of each case. However, the unpredictability as a result of inconsistency can be reduced by following some general rules, as Staring and Waddell say that the proximate cause is not necessarily consistent with each other as long as there are some reliable principal approaches applied by the courts (Lonergan, 2011).

First, where an initial peril sets in motion a subsequent peril to be occurred to set up a loss, the proximate cause will be the initial peril, forcing the subsequent peril to be irrelevant. The leading cases are Leyland Shipping Co Ltd $\mathrm{v}$ Norwich Union Fire Insurance Society Ltd and Sealion Shipping Ltd v Valiant Insurance Co. The former shows that the firing of the torpedo was able to be the proximate cause of the loss, although the loss itself was a consequence of the subsequent peril in the form of a gale. The latter also demonstrates that where three consecutive machinery breakdowns occurred led to a question of whether the breakdowns were separately recoverable or jointly indemnified. It was held that there was only one occurrence of the loss because the initial breakdown, which was the proximate cause of the loss, set the other breakdown ongoing. The decision of these cases is highly based on which one is the most efficient peril to cause the loss between two or more possible perils occurred. This common principle is described by Colinvaux's as "the death blow". However, if there is an intervening cause comes into the motion, the proximate cause will be the intervening cause. It is simply the new cause is able to break the chain of causation. For example, where external perils are able to break the causation chain of deterioration of the subject-matter insured in the form of inherent vice and becomes the proximate cause of the loss.

Second, where there are two concurrent perils occur to cause a loss, one peril is excluded by the policy, and the other one is insured by the policy, the exception peril prevails. The rationale of it is to make the exclusion clause to come into effect, otherwise, it will be meaningless. However, this principle is not universally accepted. In a Canada case, Derksen v Ontario Ltd, where the judges refused the principle by stipulating that the principle should be interpreted narrowly by inserting explicit excluded perils into the policy, otherwise the principle was inoperative.

Moreover, David and Caplan argue that this principle may not be suitable when perils are interdependent because if an excluded peril is a subsequent peril and the initial peril is an insured peril, a single peril will prevail over concurrent causes because those perils have connected each other, and the initial peril is likely to be the proximate cause according to the death blow principle. It shows that this principle may not be an absolute rule. The courts tend to identify a single proximate cause before considering a possibility of the occurrence of the concurrent causes. It can be seen from the current holding of the courts, where perils of the sea would be the proximate cause to the loss, although the perils operated concurrently with certain excluded perils, for example, inherent vice. However, apart from this inconsistency, this principle has been recognized in some cases, which demonstrate the principle is still relevant.

Third, where there are two perils operating concurrently, one is uninsured, and the other is insured, the loss is recoverable due to the operation of the insured peril. However, this principle is debatable. According to Hamblen J, this principle is only suitable in the case of two concurrent interdependent causes, not to concurrent independent causes. However, if this principle is only for the interdependent causes, it will be contrary to the death blow principle. It is because there is only a single proximate cause in two causes which each other has a necessary condition of the occurrence of the other, and the proximate cause is only the cause that affects efficiently to cause a loss. In other words, the existence of the concurrent interdependent causes is questionable. Hence, it may be appropriate for this principle to apply to independent causes. It is because neither cause acts upon each other to cause a loss, and the determination to conclude the proximate cause of the loss will be based on a construction of the policy. Until recently, there is no authority which defined the distinction between independent causes and interdependent causes of loss comprehensively, except the "but for" test will be satisfied for the former causes, and the later causes it will not.

Last but not least, in a recent case, Atlasnavious-Navegacao Lda v Navigators Insurance Co Ltd (The B Atlantic), where a ship was used by unidentified third parties to deliver $132 \mathrm{~kg}$ of cocaine; however, the drugs were discovered by Venezuela authorities, who ordered to detain her immediately. Then, the assured proceeded a recovery for her constructive total loss under a war risks 
policy. The assured argued that the detention was caused by The Malicious Acts by the drug smugglers, which fell under clause, while the insurer contended by relying on an exclusion for detentions due to infringement of customs regulations under clause The court held that the loss was irrecoverable by declining the smuggling of drugs fell within the scope of "a person acting maliciously". The court scrutinized the standard clause at the time when it was drafted and found that malicious acts should have an element of spite to harm the ship; on the contrary, the smugglers presumably wished her voyage successfully to reach the destined port in order to deliver the drugs.

Accordingly, the reliance of clause was dismissed, and the proximate cause was fell within clause. The court also considered the occurrence of concurrent cause. However, even if the smugglers' attempt was regarded as "acting maliciously", the loss would be still irrecoverable as a result of the operation of the exclusion clause. This case shows that although it reaffirms the principle established by The Wayne Tank, it takes priority to look for a single proximate cause before considering two causes operating concurrently. Interestingly, it sets up a way to interpret the meaning of particular standard clauses in a policy by not merely referring to the intentions of the parties but also considering the minds of the drafters at the time when they were arranged.

Consequently, this new approach suggests that neither insurers nor assureds may be able to interpret their new incorporation terms in an insurance policy freely only based on their intentions, leaving them to be a subject of a judicial decision by the courts. It is because, following this decision, the interpretation of the contextual meaning of standard clauses in a policy is no longer a subject of a judicial decision but a question of law which should refer back to the intentions at the time when the clauses were made by looking at previous relevant authorities. It is a crucial step to reduce issues of inconsistent interpretation. Therefore, consistency is probably not the true yardstick to find out the best rule in the application of the proximate cause because it is not easy to reconcile the application of the proximate cause perfectly. A question of law in the form of the latest cause has been replaced by the efficiency rule. The new rule should be based on the intentions of the parties and the commonsense view, where the courts potentially have different reasonings based on the facts in every case. However, The B Atlantic is an important precedent to encourage a consistent interpretation of standard clauses, and the three principal approaches, as mentioned above, provide reasonable guidance for the courts to make the results to be more predictable and coherent.

\section{Conclusion}

This piece has looked at the impact of the development of the causation rules in marine insurance after the enactment of the MIA 1906. The efficiency test is now be regarded as a historical precedent of the causation rules. What is clear is that the operation of the efficiency test alters the rule which previously relied on a question of law by looking at the latest cause of the loss to recognize a question of fact by measuring the most predominant cause of the loss. However, it does not mean that the latest cause of the loss is automatically disregarded; an immediate cause may be the proximate if it has an efficient and predominant effect to cause the loss. For example, an intervening cause usually occurs immediately before the loss. Hence, commonly, in the absence of an intervening cause, the initial peril is likely more efficient than the subsequent peril to cause a loss. In addition, the test of commons sense view and the assessment of both parties' intentions in the policy work as a supplementary examination for the courts to determine the proximate cause. The supplementary examination is necessary to maintain logical reasoning and the notion of the freedom of contract. In terms of concurrent causes, which peril should be operative will be looked at the list of perils that have been mutually agreed by both parties in the policy. The main proposition is that the excluded perils prevail over the insured perils, while the uninsured perils are taken over by the insured perils. However, the concurrent causes do not exist in a situation where there are internal causes of the subject-matter insured and fortuitous external perils setting up a loss. Perils exist in a great number of forms. The application of the proximate cause is suitable to support the nature of the insurance policy, which does not cover an inevitable loss. Consequently, a question of facts from each case is the starting point to decide which perils have a potential efficient contribution to cause a loss. Once a peril has been regarded as the proximate cause, the courts will look into the policy to determine whether the insurer is liable or not. In other words, the list of perils in the policy will be the determining factor of indemnity. 


\section{References}

Abaei, M. M., Arzaghi, E., Abbassi, R., Garaniya, V., Chai, S., \& Khan, F. (2018). A robust risk assessment methodology for safety analysis of marine structures under storm conditions. Ocean Engineering, 156, 167-178. https://doi.org/10.1016/j.oceaneng.2018.02.016

Abbott, J. K., \& Holland, D. S. (2013). Protecting marine ecosystems in fishery regulation. In J. F. Shogren (Ed.), Encyclopedia of Energy, Natural Resource, and Environmental Economics (pp. 206-214). Elsevier. https://doi.org/10.1016/B978-0-12-375067-9.00049-8

Akyuz, E. (2015). A hybrid accident analysis method to assess potential navigational contingencies: The case of ship grounding. Safety Science, 79, 268-276. https://doi.org/10.1016/j.ssci.2015.06.019

Appleby, T., Studley, M., Moorhouse, B., Brown, J., Staddon, C., \& Bean, E. (2021). Sea of possibilities: Old and new uses of remote sensing data for the enforcement of the Ascension Island marine protected area. Marine Policy, 127, 103184. https://doi.org/10.1016/j.marpol.2018.06.012

Chen, P., Huang, Y., Mou, J., \& van Gelder, P. H. A. J. M. (2019). Probabilistic risk analysis for ship-ship collision: State-of-the-art. Safety Science, 117, 108-122. https://doi.org/10.1016/j.ssci.2019.04.014

Dupré, D., \& Perluss, P. (2016). Mastering risks: An illusion: Truth and tropes on jeopardy. Research in International Business and Finance, 37, 620-628. https://doi.org/10.1016/j.ribaf.2015.12.001

Feichtner, I. (2020). Contractor liability for environmental damage resulting from deep seabed mining activities in the area. Marine Policy, 114, 103502. https://doi.org/10.1016/j.marpol.2019.04.006

Fu, G., Xie, X., Jia, Q., Li, Z., Chen, P., \& Ge, Y. (2020). The development history of accident causation models in the past 100 years: 24Model, a more modern accident causation model. Process Safety and Environmental Protection, 134, 47-82. https://doi.org/10.1016/j.psep.2019.11.027

Hee, D. D., Pickrell, B. D., Bea, R. G., Roberts, K. H., \& Williamson, R. B. (1999). Safety Management Assessment System (SMAS): a process for identifying and evaluating human and organization factors in marine system operations with field test results. Reliability Engineering \& System Safety, 65(2), 125-140. https://doi.org/10.1016/S0951-8320(98)000957

Kar, A. K., \& Navin, L. (2021). Diffusion of blockchain in insurance industry: An analysis through the review of academic and trade literature. Telematics and Informatics, 58, 101532. https://doi.org/10.1016/j.tele.2020.101532

Krauss, A. D. (2021). Chapter 16 - Effect of climate change on the insurance sector. In T. M. Letcher (Ed.), The Impacts of Climate Change (pp. 397-436). Elsevier. https://doi.org/10.1016/B978-0-12-822373-4.00014-8

Leong, S. H., Pellegrini, C. B., \& Urga, G. (2020). The contribution of shadow insurance to systemic risk. Journal of Financial Stability, 51, 100778. https://doi.org/10.1016/j.jfs.2020.100778

Lonergan, M. (2011). Potential biological removal and other currently used management rules for marine mammal populations: A comparison. Marine Policy, 35(5), 584-589. https://doi.org/10.1016/j.marpol.2011.01.020

NG, J. M. J. (2010). No Title. The Asian Journal of Shipping and Logistics, 26(1), 181-184. https://doi.org/10.1016/S2092-5212(10)80017-3 
Nwafor, N. A., \& Walker, T. R. (2020). Rethinking marine insurance and plastic pollution: food for thought. Resources, Conservation and Recycling, 161, 104950. https://doi.org/10.1016/j.resconrec.2020.104950

Sabela-Rikhotso, P. T. Z., van Niekerk, D., \& Nemakonde, L. D. (2021). A critical analysis of the legal frameworks governing oil spill management in South Africa. Marine Policy, 127, 104433. https://doi.org/10.1016/j.marpol.2021.104433

Sheng, X. U., Lu, B., \& Yue, Q. (2021). Impact of sci-tech finance on the innovation efficiency of China's marine industry. Marine Policy, 133, 104708. https://doi.org/10.1016/j.marpol.2021.104708

Stebbings, E., Papathanasopoulou, E., Hooper, T., Austen, M. C., \& Yan, X. (2020). The marine economy of the United Kingdom. Marine Policy, 116, 103905. https://doi.org/10.1016/j.marpol.2020.103905

Tiller, R., \& Richards, R. (2018). Ocean futures: Exploring stakeholders' perceptions of adaptive capacity to changing marine environments in Northern Norway. Marine Policy, 95, 227-238. https://doi.org/10.1016/j.marpol.2018.04.001

Van den Bergh, J. C. J. M., Nunes, P. A. L. D., Dotinga, H. M., Kooistra, W. H. C. F., Vrieling, E. G., \& Peperzak, L. (2002). Exotic harmful algae in marine ecosystems: an integrated biological-economic-legal analysis of impacts and policies. Marine Policy, 26(1), 59-74. https://doi.org/10.1016/S0308-597X(01)00032-X

Zheng, H., Shang, M., \& Zhao, X. (2020). Chinese policy on fishery insurance: Evolution, characteristics and challenges. Marine Policy, 119, 104099. https://doi.org/10.1016/j.marpol.2020.104099 